\title{
Estudo comparativo de algumas provas funcionais do fluido ruminal e de metabólitos sangüíneos de bovinos e bubalinos
}

\author{
José Diomedes Barbosa ${ }^{2}$, Sandra Cristina de Ávila², Regina Valéria da Cunha Dias ${ }^{3}$, \\ Imke Barbara Pfeifer ${ }^{2}$ e Carlos Magno Chaves de Oliveira ${ }^{2}$
}

\begin{abstract}
Barbosa J.D., Ávila S.C., Dias R.V.C., Pfeifer I.B. \& Oliveira C.M.C. 2003. [A comparative study of some functional exams of the ruminal fluid and of some blood metabolites of cattle and buffaloes.] Estudo comparativo de algumas provas funcionais do fluido ruminal e de metabólitos sangüíneos de bovinos e bubalinos. Pesquisa Veterinária Brasileira 23(1):33-37. Central de Diagnóstico Veterinário, Universidade Federal do Pará, Rua Maximino Porpino da Silva 1000, Castanhal, PA 68740-080, Brazil. E-mail: diomedes@ufpa.br

In adult buffaloes and cattle in the Amazonian Region, fed elephant grass (Pennisetum purpureum), the following values of the ruminal fluid were determined: colour, odor, viscosity, sedimentation, flotation, $\mathrm{pH}$, the reduction of methylene blue, glucose fermentation, total acidity, total number of protozoa, the amount of chlorides, reduction of nitrites and the predominant group of bacteria. In the blood serum, the amounts of chlorides, total proteins and urea were also established. A comparison between the parameters observed in buffaloes and cattle did not show significant differences, with exception of the amount of chlorides and the number and distribution of protozoa. In buffaloes the amount of chlorides was lower and the number of protozoa was higher than those observed in cattle; additionally in buffaloes the small protozoa predominated, to the contrary of cattle, in which the large protozoa predominated.
\end{abstract}

INDEX TERMS: Ruminal fluid, blood metabolites, cattle, buffaloes.

RESUMO.- No fluido ruminal de búfalos e de bovinos da Região Amazônica, alimentados com capim-elefante (Pennisetum purpureum) var. Cameron, foram determinados os seguintes parâmetros: cor, odor, viscosidade, sedimentação, flotação, $\mathrm{pH}$, redução do azul de metileno, fermentação da glicose, acidez total, número total de protozoários, teor de cloretos, redução de nitrito e grupo de bactérias predominantes. No soro sangǘneo também foram avaliados os teores de cloretos, proteínas totais e uréia. A comparação desses dados não resultou em diferenças significativas entre as duas espécies, com exceção do teor de cloretos e do número e distribuição dos protozoários. Nos búfalos, os teores de cloretos foram mais baixos e o número de protozoários foi maior do que o observado em bovinos; adicionalmente nos búfalos predo-

\footnotetext{
${ }^{1}$ Aceito para publicação em 30 de janeiro de 2003.

${ }^{2}$ Central de Diagnóstico Veterinário (CEDIVET), Universidade Federal do Pará (UFPA), Rua Maximino Porpino 1000, Castanhal, PA 68740-080, Brasil. Email: diomedes@ufpa.br

${ }^{3}$ Escola Superior de Agricultura de Mossoró (ESAM), Mossoró, RN 59625-900.
}

minaram os protozoários pequenos, enquanto em bovinos preponderaram os protozoários grandes.

TERMOS DE INDEXAÇÃO: Fluido ruminal, metabólitos sangüíneos, bovinos, búfalos.

\section{INTRODUÇÃO}

Os processos fermentativos que ocorrem no rúmen são responsáveis pela síntese da proteína microbiana, vitaminas e dos ácidos graxos voláteis. A qualidade e a quantidade destes produtos estão na dependência da natureza do alimento oferecido, da forma como são ofertados, bem como de fatores fisiológicos pertinentes ao ambiente ruminal, como temperatura, anaerobiose e $\mathrm{pH}$.

A busca por uma melhor produtividade dentro da exploração de bovinos e bubalinos está promovendo a mudança das criações extensivas para semi-extensivas ou até mesmo intensivas. Essa mudança, muitas vezes, vem acompanhada de problemas, principalmente aqueles ligados ao sistema digestivo.

Acompanhando essa evolução, análises da função ruminal (Holtenius et al. 1959) assumiram grande importância no di- 
agnóstico destas alterações. De fato, a avaliação das atividades bioquímicas microbianas normais e patológicas dos reservatórios gástricos auxilia bastante no estabelecimento da etiologia, assim como orienta a terapêutica e a profilaxia adequada.

Nessa área, porém, a maioria dos trabalhos se refere a bovinos, o que torna necessário o estabelecimento dos parâmetros de normalidade do conteúdo ruminal para outras espécies, em função das reconhecidas diferenças na capacidade digestiva e hábitos alimentares que possuem (Hofmann 1989, Bezerra 2001).

Embora no Brasil o rebanho bubalino atinja aproximadamente 1.500 .000 de cabeças, dois terços dos quais na Região Norte (Anualpec1996), há grande escassez de estudos nesta espécie, principalmente no que tange às análises do fluido ruminal nas condições climáticas e de manejo da região norte do Brasil.

Desta forma, a presente pesquisa teve como objetivo determinar e comparar as características do líquido ruminal de alguns metabólitos sanguííneos de bovinos e bubalinos criados em sistema intensivo na região Bragantina do Estado do Pará.

\section{MATERIAL E MÉTODOS}

O experimento foi realizado na Central de Diagnóstico Veterinário (Cedivet) em conjunto com a Central de Biotecnologia de Reprodução Animal (Cebran), da Universidade Federal do Pará, município de Castanhal, PA.

Foram utilizados seis animais, sendo três bovinos mestiços e três búfalos da raça Murrah, clinicamente sadios, de ambos os sexos, mantidos em baias de alvenaria e submetidos à uma dieta exclusiva de capim-elefante (Penisetum purpureum var. Cameron). Os animais eram alimentados duas vezes por dia, às 6:30h e 17:00h. Os mesmos tiveram livre acesso a sal mineral comercial e a água.

A dieta foi analisada no início e 15 dias depois, ao término do experimento. $\mathrm{O}$ capim da dieta (folhas e colmos) foi cortado, durante a estação chuvosa, com cerca de 70 dias de idade. As amostras recémcortadas foram pré-dessecadas durante 72 horas a $65^{\circ} \mathrm{C}$. Após a présecagem foram moídas para atingirem a granulometria de $1 \mathrm{~mm}$. Foram feitas determinações de matéria seca (MS) e proteína bruta (PB), tal como descritas pela AOAC (1990) e de Fibra Detergente Neutro (FDN) e Fibra Detergente Ácido (FDA), descritas por Van Soest et al. (1991).

As coletas do líquido ruminal foram realizadas em jejum (0h), 2:30 e 5:00 horas após a alimentação, durante um período de 5 dias. O líquido ruminal foi coletado utilizando-se uma sonda acoplada a uma bomba de vácuo. Os primeiros $200 \mathrm{ml}$ foram desprezados com intuito de minimizar o efeito alcalinizante da saliva sobre o $\mathrm{pH}$.

O exame do líquido ruminal era realizado imediatamente após a coleta e constava das análises macroscópicas de cor, odor, viscosidade, aspecto, tempo, sedimentação e flotação (TSF). Dentro dos exames físico-químicos foram avaliados o $\mathrm{pH}$, a redução do azul de metileno (RAM), a redução de nitrito, a acidez total e a fermentação da glicose, tal como descritos por Rosenberger (1993). A determinação de cloretos foi realizada utilizando-se kits labtest.

No exame microbiológico, os protozoários foram avaliados pela densidade, motilidade, porcentagem de pequenos, médios e grandes e contagem total (Rosenberger 1993). Em relação às bactérias foram realizadas análises para o grupo predominante (Baumgartner 1983).
A determinação no soro sangüíneo das concentrações de uréia e cloretos foram realizadas através de kits labtest, enquanto a concentração de proteína total foi determinada utilizando-se um refratômetro (HRM-18), que avalia a densidade do plasma como descrito por Kaneko (1989).

Para avaliação estatística foi feita uma análise de variância dos dados e as médias foram submetidas ao teste de Tukey, assumindose $5 \%$ de probabilidade.

\section{RESUL TADOS E DISCUSSÃO}

A composição bromatológica do capim-elefante encontra-se no Quadro 1.

Ao exame macroscópico do líquido ruminal, a cor, em ambas as espécies, variou de verde-oliva ao amarelo-palha, $o$ que é compatível com o tipo de alimentação que foi oferecido aos animais (Campos Neto 1977, Dirksen 1981, Dirksen et al.1993, Garry 1993).

A consistência do líquido ruminal, em ambas as espécies, era ligeiramente viscosa independente da hora das coletas. A semelhança deste dado entre as espécies deve-se ao fato que os bubalinos e os bovinos receberam o mesmo tipo de alimentação, com a mesma composição e no mesmo horário. Esse aspecto ligeiramente viscoso foi estabelecido como padrão fisiológico na espécie bovina (Dirksen et al.1993).

O odor do conteúdo ruminal nas espécies bubalina e bovina, em todas as coletas, apresentou-se aromático, porém mais forte na espécie bubalina quando comparado com o da espécie bovina. Esse odor aromático também já foi observado em bovinos (Garry 1993, Dirksen et al.1993). Já o odor mais forte, porém normal, do líquido ruminal de bubalinos possivelmente deve-se a alguma particularidade do rúmen desta espécie, ainda por ser determinada.

O TSF, que mede a capacidade de fermentação através da produção de gás pelas bactérias ruminais, durou, em média, 227,9 e 240,5 segundos, respectivamente, para bovinos e para bubalinos, não havendo diferença significativa entre as coletas e nem entre as espécies estudadas (Quadro 4). Esses valores encontram-se no limite mínimo, mas ainda dentro do padrão fisiológico para bovinos, que é de 4 a 8 minutos (Costa 1992, Dirksen et al. 1993, Garry 1993).

Nos Quadros 2 e 3 estão listadas as médias de cada parâmetro do líquido ruminal na primeira, segunda e terceira coleta de bovinos e bubalinos, respectivamente. No Quadro 4 encontra-se a comparação dos parâmetros do líquido ruminal de bovinos e de bubalinos.

Os valores de $\mathrm{pH}$ encontrados nos bovinos ficaram em torno de 6,8 e, nos bubalinos, 6,84, não havendo diferença significativa entre as coletas e nem entre as espécies testadas (Quadro 4). Fisiologicamente, o pH do fluido ruminal pode variar de 5,5 a 7,4 dependendo do tipo de alimentos ingeridos, da forma como esses são ofertados e do tempo de cole-

Quadro 1. Composição bromatológica média do capim-elefante

\begin{tabular}{lcccc}
\hline Parâmetro & $\begin{array}{c}\text { MS } \\
(\mathrm{g} / \mathrm{kg})\end{array}$ & $\begin{array}{c}\text { PB } \\
(\mathrm{g} / \mathrm{kgMS})\end{array}$ & $\begin{array}{c}\text { FDN } \\
(\mathrm{g} / \mathrm{kgMS})\end{array}$ & $\begin{array}{c}\text { FDA } \\
(\mathrm{g} / \mathrm{kgMS})\end{array}$ \\
\hline Média & 861,1 & 90,0 & 694,1 & 38,45
\end{tabular}


Quadro 2. Aspectos físico-químicos e microbiológicos do líquido ruminal de bovinos

\begin{tabular}{|c|c|c|c|c|c|c|c|}
\hline \multirow{2}{*}{$\begin{array}{l}\text { Parâmetros do } \\
\text { líquido ruminal }\end{array}$} & \multirow[t]{2}{*}{ Unidade } & \multicolumn{2}{|c|}{$1^{\text {a }}$ coleta } & \multicolumn{2}{|c|}{$2^{\mathrm{a}}$ coleta } & \multicolumn{2}{|c|}{$3^{\mathrm{a}}$ coleta } \\
\hline & & Média & Ep & Média & Ep & Média & Ep \\
\hline Sedimentação e flotação & seg. & $210^{\mathrm{a}}$ & 96,4 & $217,7^{\mathrm{a}}$ & 84,6 & $256,1^{\mathrm{a}}$ & 92,4 \\
\hline $\mathrm{pH}$ & grau & $6,80^{\mathrm{a}}$ & 0,31 & $6,76^{\mathrm{a}}$ & 0,26 & $6,83^{\mathrm{a}}$ & 0,29 \\
\hline Azul de metileno & seg. & $87,2^{\mathrm{a}}$ & 67,8 & $72,8^{\mathrm{a}}$ & 48,4 & $88,3^{\mathrm{a}}$ & 78,5 \\
\hline Fermentação da glicose & $\mathrm{mL} / \mathrm{h}$ & $2,37^{\mathrm{a}}$ & 1,34 & $2,15^{\mathrm{a}}$ & 0,91 & $2,37^{\mathrm{a}}$ & 1,14 \\
\hline Acidez total & $\mathrm{UC}$ & $15,2^{\mathrm{a}}$ & 5,31 & $18,7^{\mathrm{a}}$ & 4,38 & $16,6^{\mathrm{a}}$ & 3,48 \\
\hline Teor de cloretos & $\mathrm{MEq} / \mathrm{L}$ & $14,1^{\mathrm{a}}$ & 2,53 & $16,7^{\mathrm{a}}$ & 6,34 & $15,1^{\mathrm{a}}$ & 4,32 \\
\hline \multicolumn{8}{|l|}{ Redução de nitrito } \\
\hline $0,2 \mathrm{ml}$ & $\min$. & $5,00^{\mathrm{a}}$ & 0,00 & $5,00^{\mathrm{a}}$ & 0,00 & $5,00^{\mathrm{a}}$ & 0,00 \\
\hline $0,5 \mathrm{ml}$ & $\min$. & $8,50^{\mathrm{a}}$ & 5,30 & $7,50^{\mathrm{a}}$ & 4,52 & $8,75^{\mathrm{a}}$ & 5,28 \\
\hline $0,7 \mathrm{ml}$ & $\min$. & $11,0^{\mathrm{a}}$ & 5,68 & $8,75^{\mathrm{a}}$ & 5,69 & $10,0^{\mathrm{a}}$ & 6,74 \\
\hline \multicolumn{8}{|l|}{ Protozoários } \\
\hline Pequenos & $\%$ & $39,0^{\mathrm{a}}$ & 16,6 & 46,7 & 11,5 & $45,8^{\mathrm{a}}$ & 7,93 \\
\hline Médios & $\%$ & $34,0^{\mathrm{a}}$ & 8,43 & $31,7^{\mathrm{ab}}$ & 7,18 & $26,7^{\mathrm{a}}$ & 7,78 \\
\hline Grandes & $\%$ & $27,0^{\mathrm{a}}$ & 13,4 & $21,7^{a}$ & 8,35 & $27,5^{\mathrm{a}}$ & 10,5 \\
\hline Protozoários totais & $\mathrm{mL}$ & $107022^{\mathrm{a}}$ & 45145 & $120384^{a}$ & 45772 & $111932^{\mathrm{a}}$ & 43836 \\
\hline Bactérias predominantes & & \multicolumn{2}{|c|}{ Gram negativas } & \multicolumn{2}{|c|}{ Gram negativas } & \multicolumn{2}{|c|}{ Gram negativas } \\
\hline
\end{tabular}

Quadro 3. Aspectos físico-químicos e microbiológicos do líquido ruminal de bubalinos

\begin{tabular}{|c|c|c|c|c|c|c|c|}
\hline \multirow{2}{*}{$\begin{array}{l}\text { Parâmetros do } \\
\text { líquido ruminal }\end{array}$} & \multirow[t]{2}{*}{ Unidade } & \multicolumn{2}{|c|}{$1^{\mathrm{a}}$ coleta } & \multicolumn{2}{|c|}{$2^{\mathrm{a}}$ coleta } & \multicolumn{2}{|c|}{$3^{\mathrm{a}}$ coleta } \\
\hline & & Média & Ep & Média & Ep & Média & Ep \\
\hline Sedimentação e flotação & seg. & $259,2^{\mathrm{a}}$ & 80,5 & $208,9^{\mathrm{a}}$ & 85,1 & $253,5^{\mathrm{a}}$ & 79,5 \\
\hline $\mathrm{pH}$ & grau & $6,82^{\mathrm{a}}$ & 0,37 & $6,90^{\mathrm{a}}$ & 0,33 & $6,80^{\mathrm{a}}$ & 0,24 \\
\hline Azul de metileno & seg. & $68,4^{\mathrm{a}}$ & 41,5 & $59,5^{\mathrm{a}}$ & 28,3 & $57,3^{\mathrm{a}}$ & 29,3 \\
\hline Fermentação da glicose & $\mathrm{mL} / \mathrm{h}$ & $2,60^{\mathrm{a}}$ & 1,15 & $1,95^{\mathrm{a}}$ & 0,89 & $2,27^{\mathrm{a}}$ & 1,22 \\
\hline Acidez total & $\mathrm{UC}$ & $16,4^{\mathrm{a}}$ & 4,19 & $18,6^{\mathrm{a}}$ & 4,89 & $20,0^{\mathrm{a}}$ & 4,22 \\
\hline Teor de cloretos & $\mathrm{MEq} / \mathrm{L}$ & $11,4^{\mathrm{a}}$ & 2,17 & $12,1^{\mathrm{a}}$ & 4,62 & $13,9^{\mathrm{a}}$ & 5,38 \\
\hline \multicolumn{8}{|l|}{ Redução de nitrito } \\
\hline $0,2 \mathrm{ml}$ & $\min$. & $5,00^{\mathrm{a}}$ & 0,00 & $5,00^{\mathrm{a}}$ & 0,00 & $5,00^{\mathrm{a}}$ & 0,00 \\
\hline $0,5 \mathrm{ml}$ & $\min$. & $7,92^{\mathrm{a}}$ & 4,98 & $5,42^{\mathrm{a}}$ & 1,44 & $5,00^{\mathrm{a}}$ & 0,00 \\
\hline $0,7 \mathrm{ml}$ & $\min$. & $9,58^{\mathrm{a}}$ & 7,82 & $6,67^{\mathrm{a}}$ & 3,26 & $6,25^{\mathrm{a}}$ & 2,26 \\
\hline \multicolumn{8}{|l|}{ Protozoários } \\
\hline Pequenos & $\%$ & $55,8^{\text {a }}$ & 14,4 & $55,0^{\mathrm{a}}$ & 6,74 & $59,2^{\mathrm{a}}$ & 9,00 \\
\hline Médios & $\%$ & $30,0^{\mathrm{a}}$ & 8,53 & $30,8^{\mathrm{a}}$ & 2,89 & $25,8^{\mathrm{a}}$ & 5,15 \\
\hline Grandes & $\%$ & $14,2^{\mathrm{a}}$ & 6,69 & $14,2^{\mathrm{a}}$ & 6,69 & $15,0^{\mathrm{a}}$ & 9,05 \\
\hline Protozoários totais & $\mathrm{mL}$ & $169339^{\mathrm{a}}$ & 51568 & $133832^{\mathrm{a}}$ & 37845 & $134427^{\mathrm{a}}$ & 67107 \\
\hline Bactérias predominantes & & \multicolumn{2}{|c|}{ Gram negativas } & \multicolumn{2}{|c|}{ Gram negativas } & \multicolumn{2}{|c|}{ Gram negativas } \\
\hline
\end{tabular}

ta do fluido ruminal após a última refeição, que, neste experimento, foram iguais para as duas espécies.

A RAM e o pH são dados que podem ser usados com facilidade para diagnosticar ou descartar alterações que ocorram no ambiente ruminal. $O$ tempo de RAM encontrado na espécie bovina foi, em média, 82,8 segundos e, na espécie bubalina, 61,7 segundos, evidenciando uma ligeira inferioridade na espécie bubalina, que porém não constitui diferença significativa nem entre as espécies e nem entre as coletas (Quadro 4). O tempo de RAM está relacionado com a qualidade do alimento ingerido e pode chegar a até 6 minutos, sendo que em animais que recebem alimentos ricos em carboidratos não-estruturais esse tempo de redução pode ser inferior a 1 minuto (Dirksen et al.1993).

Com relação à fermentação da glicose, que consiste em avaliar-se a produção de gás produzida no ambiente ruminal, os valores encontrados nas duas espécies foram muito semelhantes com 2,29 mL/h em bovinos e 2,27 mL/h em bubalinos. Segundo Dirksen et al. (1993), a quantidade normal de gás produzida em uma hora é de $1 \mathrm{a} 2 \mathrm{ml}$, portanto, os valores desse trabalho estão um pouco elevados, porém dentro do normal levando-se em consideração um desvio padrão de 1,10 $\mathrm{ml} / \mathrm{h}$ em ambas as espécies (Quadro 4).

A determinação da acidez total vem sendo utilizada como exame complementar no diagnóstico dos distúrbios digestivos caracterizados por um refluxo do conteúdo abomasal para o rúmen (Dirksen et al. 1993). Neste experimento, ficou demonstrado que não houve diferença significativa entre as espécies bovina e bubalina, porém os valores encontrados nos búfalos foram inferiores aos verificados em bovinos por Oliveira (1991), que observou valores médios de 26 UC em pastagens de verão. Como a acidez total do líquido ruminal 
Quadro 4. Médias das análises do líquido ruminal de bovinos e bubalinos

\begin{tabular}{|c|c|c|c|c|c|}
\hline \multirow{2}{*}{$\begin{array}{l}\text { Parâmetros do } \\
\text { líquido ruminal }\end{array}$} & \multirow[t]{2}{*}{ Unidade } & \multicolumn{2}{|c|}{ Bovinos } & \multicolumn{2}{|c|}{ Bubalinos } \\
\hline & & Média & Ep & Média & Ep \\
\hline Sedimentação e flotação & seg. & $227,9^{a}$ & 90,5 & $240,5^{a}$ & 82,6 \\
\hline $\mathrm{pH}$ & grau & $6,80^{\mathrm{a}}$ & 0,28 & $6,84^{\mathrm{a}}$ & 0,31 \\
\hline Azul de metileno & seg. & $82,8^{a}$ & 64,4 & $61,7^{\mathrm{a}}$ & 32,9 \\
\hline Fermentação da glicose & $\mathrm{mL} / \mathrm{h}$ & $2,29^{a}$ & 1,10 & $2,27^{\mathrm{a}}$ & 1,10 \\
\hline Acidez total & $\mathrm{UC}$ & $16,8^{\mathrm{a}}$ & 4,49 & $18,3^{\mathrm{a}}$ & 4,57 \\
\hline Teor de cloretos & $\mathrm{MEq} / \mathrm{L}$ & $15,3^{\mathrm{a}}$ & 4,74 & $12,5^{b}$ & 4,29 \\
\hline \multicolumn{6}{|l|}{ Redução de nitrito } \\
\hline $0,2 \mathrm{ml}$ & $\min$. & $5,00^{\mathrm{a}}$ & 0,00 & $5,00^{\mathrm{a}}$ & 0,00 \\
\hline $0,5 \mathrm{ml}$ & $\min$. & $8,25^{\mathrm{a}}$ & 4,91 & $6,11^{\mathrm{a}}$ & 3,19 \\
\hline $0,7 \mathrm{ml}$ & $\min$. & $9,92^{\mathrm{a}}$ & 5,14 & $7,50^{\mathrm{a}}$ & 5,97 \\
\hline \multicolumn{6}{|l|}{ Protozoários } \\
\hline Pequenos & $\%$ & $43,8^{\mathrm{a}}$ & 12,3 & $56,7^{\mathrm{a}}$ & 10,4 \\
\hline Médios & $\%$ & $30,8^{a}$ & 8,1 & $28,9^{\mathrm{a}}$ & 6,22 \\
\hline Grandes & $\%$ & $25,4^{\mathrm{a}}$ & 10,8 & $14,5^{b}$ & 7,35 \\
\hline Protozoários totais & $\mathrm{mL}$ & $113111^{\mathrm{a}}$ & 438 & $145866^{\mathrm{a}}$ & 5502 \\
\hline Bactérias predominantes & & Gram ne & ativas & Gram ne & ativas \\
\hline
\end{tabular}

está relacionada à produção de AGV (Briggs et al. 1957), poder-se-ia explicar a semelhança dos dados entre bovinos e bubalinos, pelo fato que esses animais tiveram o mesmo regime alimentar.

O número de protozoários no fluido ruminal oscila na dependência da composição da dieta, da hora de arraçoamento e do local da coleta dentro do rúmen. Apesar destes critérios terem sido estabelecidos para as duas espécies em estudo, o número de protozoários foi significativamente mais alto $(\mathrm{p}<0,05)$ na espécie bubalina, porém ficando dentro dos padrões normais estabelecidos para bovinos (Dirksen et al. 1993).

Na distribuição dos protozoários só foram observadas diferenças estatísticas significativas $(\mathrm{p}<0,05)$ no porcentual de protozoários médios entre a primeira e a terceira coleta nos bovinos. Na comparação entre as duas espécies, o número de protozoários pequenos foi estatisticamente mais alto $(p<0,05)$ em búfalos (Quadro 4).

A observação microscópica da microbiota ruminal pode ser um recurso útil, e até decisivo para o esclarecimento da natureza das afecções nesses compartimentos. $O$ grupo de bactérias predominantes encontrado nesse estudo, em ambas as espécies, foi o Gram-negativo, o que está de acordo com os dados encontrados por Dirksen et al. (1993). A mudança no grupo de bactérias predominantes no fluido ruminal é determinada pelo tipo de alimentação a que o animal é submetido. Uma alimentação rica em carboidratos não-estruturais favorece o crescimento do grupo de bactérias Gram-positivas (Dirksen 1981).

$\mathrm{O}$ conjunto dos dados referentes à acidez total e à concentração de cloretos no líquido ruminal constitui um parâmetro que auxilia no diagnóstico das obstruções na passagem da digesta pelo abomaso e pelos intestinos. As enfermidades relacionadas com o abomaso, tais como o refluxo do conteúdo abomasal para o rúmen-retículo, o deslocamento, a torção e o estrangulamento podem elevar a concentração de cloretos a níveis de 30 a $100 \mathrm{mmol} / \mathrm{L}$; normalmente essa concentração se situa entre 15 a $30 \mathrm{mmol} / \mathrm{L}$. A administração adicional de cloreto de sódio no alimento e a paralisia do intestino grosso ou delgado são também responsáveis por uma elevação na concentração de cloretos no líquido ruminal. Na comparação dos teores de cloretos entre bovinos e búfalos verifica-se que a maior concentração de cloretos obtida na espécie bovina $(15,3 \pm 4,74)$ foi estatísticamente maior $(\mathrm{P}<0,05)$ quando comparada com a espécie bubalina que obteve média de 12,5 $\pm 4,29$ (Quadro 4). Esses valores mais baixos de cloretos na espécie bubalina poderiam estar relacionados com o suposto menor consumo de cloreto de sódio devido a uma menor sudorese em consequiência de um número reduzido de glândulas sudoríparas nessa espécie animal (Muller 1982).

O teste de redução de nitrito segundo Holtenius et al. (1959) fornece conclusões sobre a atividade da microbiota que participa na redução ou na síntese de ligações nitrogenadas. Na comparação da redução de nitrito no líquido ruminal não foram evidenciadas diferenças significativas entre essas duas espécies (Quadro 4). Os valores médios, em minutos, da redução de nitrito encontrados em búfalos e bovinos ficaram dentro dos limites estabelecidos para bovinos. A redução mais rápida pode ocorrer quando o animal recebe uma alimentação com volumosos tenros, na putrefação ou no timpanismo espumoso, porém é mais lenta na deficiência alimentar e na inapetência (Dirksen et al. 1993).

Os achados referentes aos metabólitos do sangue não evidenciaram diferenças estatísticas entre as coletas e nem entre as espécies estudadas (Quadros 5, 6 e 7).

Os valores da proteína plasmática total (PPT) não variaram significativamente $(p<0,05)$ entre as duas espécies, como pode ser verificado nos Quadros 5 e 6 . A similaridade entre os valores de PPT encontrados provavelmente refletem o padrão de alimentação oferecida aos animais, pois segundo Manik et al. (1988), as concentrações de PPT estão relacionadas diretamente com as concentrações de proteína e energia da alimentação. Uma diminuição nas concentrações de PPT 
Quadro 5. Valores de uréia, cloretos e proteína total do soro de bovinos

\begin{tabular}{|c|c|c|c|c|c|c|c|}
\hline \multirow{2}{*}{$\begin{array}{c}\text { Metabólitos } \\
\text { analisados }\end{array}$} & \multirow[t]{2}{*}{ Unidade } & \multicolumn{2}{|c|}{$1^{\mathrm{a}}$ coleta } & \multicolumn{2}{|c|}{$2^{\mathrm{a}}$ coleta } & \multicolumn{2}{|c|}{$3^{\mathrm{a}}$ coleta } \\
\hline & & Média & Ep & Média & Ep & Média & Ep \\
\hline Uréia & $(\mathrm{g} / \mathrm{dL})$ & $29,9^{a}$ & 9,47 & $34,9^{\mathrm{a}}$ & 10,4 & $38,9^{\mathrm{a}}$ & 14,2 \\
\hline Cloretos & $\mathrm{MEq}$ & $109,2^{\mathrm{a}}$ & 20,3 & $120,2^{\mathrm{a}}$ & 24,3 & $115,2^{\mathrm{a}}$ & 23,7 \\
\hline Proteína total & $(\mathrm{g} / \mathrm{dL})$ & $8,80^{\mathrm{a}}$ & 1,53 & $8,48^{\mathrm{a}}$ & 1,65 & $8,83^{\mathrm{a}}$ & 1,25 \\
\hline
\end{tabular}

Quadro 6. Valores de uréia, cloretos e proteína total do soro de bubalinos

\begin{tabular}{|c|c|c|c|c|c|c|c|}
\hline \multirow{2}{*}{$\begin{array}{l}\text { Metabólitos } \\
\text { analisados }\end{array}$} & \multirow[t]{2}{*}{ Unidade } & \multicolumn{2}{|c|}{$1^{\mathrm{a}}$ coleta } & \multicolumn{2}{|c|}{$2^{\mathrm{a}}$ coleta } & \multicolumn{2}{|c|}{$3^{\mathrm{a}}$ coleta } \\
\hline & & Média & Ep & Média & Ep & Média & Ep \\
\hline Uréia & $(\mathrm{g} / \mathrm{dL})$ & $33,6^{\mathrm{a}}$ & 9,82 & $29,8^{a}$ & 10,5 & $32,8^{\mathrm{a}}$ & 4,94 \\
\hline Cloretos & MEq & $113,8^{a}$ & 19,2 & $111,8^{a}$ & 4,21 & $113,6^{a}$ & 25,3 \\
\hline Proteína total & $(\mathrm{g} / \mathrm{dL})$ & $8,62^{\mathrm{a}}$ & 1,27 & $9,15^{a}$ & 1,35 & $8,73^{a}$ & 1,16 \\
\hline
\end{tabular}

Quadro 7. Concentrações médias de uréia, cloretos e proteína total no soro de bovinos e bubalinos

\begin{tabular}{|c|c|c|c|c|c|}
\hline \multirow{2}{*}{$\begin{array}{c}\text { Parâmetros } \\
\text { do soro }\end{array}$} & \multirow[t]{2}{*}{ Unidade } & \multicolumn{2}{|c|}{ Bovino } & \multicolumn{2}{|c|}{ Bubalino } \\
\hline & & Média & Ep & Média & Ep \\
\hline Uréia & $(\mathrm{g} / \mathrm{dL})$ & $34,6^{\mathrm{a}}$ & 11,8 & $32,1^{\mathrm{a}}$ & 8,70 \\
\hline Cloretos & MEq & $114,8^{\mathrm{a}}$ & 22,6 & $113,1^{\mathrm{a}}$ & 22,4 \\
\hline Proteína total & $(\mathrm{g} / \mathrm{dL})$ & $8,70^{\mathrm{a}}$ & 1,25 & $8,83^{a}$ & 1,38 \\
\hline
\end{tabular}

pode ocorrer nas diarréias graves, no parasitism gastrointestinal e na amiloidose renal, enquanto que um aumento nas concentrações de PPT tem sido observado nos casos de hemoconcentração e de processos infecciosos crônicos (Dirksen et al.1993, Kolb 1984).

A concentração de uréia no soro sangüíneo está em relação direta com o aporte protéico da ração, com a degradabilidade da proteína, bem como da relação energia:proteína. Valores baixos de uréia no sangue são encontrados em animais que recebem alimentos com baixa concentração de proteína e, valores altos, naqueles animais que recebem dietas com excesso de proteína degradável no rúmen ou com reduzida quantidade de carboidratos não-estruturais (Wittwer 2000).

\section{CONCLUSÕES}

- Quando bovinos e bubalinos são submetidos ao mesmo tipo de alimentação, os parâmetros do líquido ruminal relacionados com as análises macroscópicas e físico-químicas são semelhantes.

- O teor de cloretos foi menor e houve um número de protozoários maior no líquido ruminal dos búfalos do que no dos bovinos, em especial de protozoários pequenos.

- Entre as duas espécies não ocorreram variações signifi- cativas nos teores sangüíneos de uréia, cloretos e proteínas totais.

\section{REFERÊNCIAS}

Anualpec. 1996. Anuário Estatístico da Produção Animal. Argos Comunicação, São Paulo. 312p.

Association of Official Analytical Chemists (AOAC) 1990. Official Methods of Analysis. Vol. 1. 15 $5^{\text {th }}$ ed. Arlington; v.I, 1117p.

Baumgartner W. 1983. Labordiagnostik in der Klauentierpraxis. 3. Untersuchung des Pansensaftes. Tierärztl. Umsch. 38:558-561.

Bezerra A.R.G.F. 2001. Parâmetros cinéticos da degradação ruminal de alimentos utilizados em zoológicos para diferentes espécies de ruminantes. Dissertação de Mestrado em Zootecnia, UFRRJ. 80p.

Briggs P.K., Nogan J.P. \& Reid R.L.1957. The effect of volatile fatty acid on rumen $\mathrm{pH}$ in sheep. Aust. J. Agric. Res. 8: 674-90.

Campos Neto O. 1977. Aspectos físico-químicos do conteúdo do rúmen e suas implicações na patogenia das enfermidades deste órgão. Comun. Cient. Fac. Med. Vet. Zootec. Univ. S. Paulo 1(1): 26-37.

Costa N.A.1992. Estudo clínico do suco de rúmen de bovinos normais em diferentes manejos de arraçoamento com palma forrageira (Palma-gigante, Opuntia ficus indica Hill). Dissertação de Mestrado, UFPE, Recife. 57p.

Dirksen G. 1981. Indigestiones en el Bovino. Schnetztor-Verlag, Konstanz. 76p.

Dirksen G., Gründer H.D. \& Stöber M.1993. Exame Clínico dos Bovinos. Guanabara Koogan, Rio de Janeiro. 419p.

Garry F. B. 1993. Indigestão em ruminantes, p. 750-783. In: Smith B. P. (ed.) Tratado de Medicina Interna de Grandes Animais: Moléstias de Eqüinos, Bovinos, Ovinos e Caprinos. Manole, São Paulo.

Hofmann R.R.1989. Evolutionary steps of ecophysiological adaptation and diversification of ruminants: a comparative view of their digestive system. Oecologia 78:443-457.

Holtenius P., Bjorck G. \& Hollund S. 1959. Die Untersuchung von Pansensaftproben. Dtsch. Tierärztl. Wschr. 66 (20):554-558.

Kaneko J.J. 1989. Clinical Biochemistry of Domestic Animals. $4^{\text {th }}$ ed. Academic Press, San Diego, California. 932p.

Kolb E. 1984. Fisiologia Veterinária. $4^{\mathrm{a}}$ ed. Guanabara Koogan, Rio de Janeiro. 612p.

Manik R.S., Srivastava A. \& Mudgal V.D. 1988. Significance of season influenced changes in haematology of Murrah buffaloes fed varying levels of dietary protein. Indian J. Anim. Prod. 4(1):22-26.

Muller P.B. 1982. Bioclimatologia Aplicada aos Animais Domésticos. $2^{\mathrm{a}}$ ed. Editora Sulina, Porto Alegre. 158 p.

Oliveira P.B. 1991. Estudo do suco ruminal de bovinos criados em regime extensivo de pastagem (Brachiaria decumbens) no município de Botucatu. Tese de Mestrado, Unesp-Botucatu, SP.

Rosenberger G. 1983. Enfermedades de los Bovinos. Tomo II. Hemisferio Sur, Montevideo. 577 p.

Van Soest P.J., Robertson J.B. \& Lewis B.A. 1991. Methods for dietary fiber, neutral detergent fiber, and non starch polysaccharides in relation to animal nutrition. J. Dairy Sci. 74: 3583-3597.

Wittwer F. 2000. Diagnóstico dos desequilíbrios metabólicos de energia em rebanhos bovinos, p. 9-22. In: González F.H.D., Barcellos J.O., Ospina H. \& Ribeiro L.A.O.(ed.) Perfil Metabólico em Ruminantes: seu uso em nutrição e doenças nutricionais. Gráfica da Universidade Federal do Rio Grande do Sul, Porto Alegre. 